\title{
CÁnOVAS. POLÍtico del SEXENIO REVOLUCIONARIO
}

por

\section{JORGE VILCHES GARCIA}

Universidad Complutense de Madrid

RESUMEN: La actitud de Cánovas durante el Sexenio Revolucionario (1868-1874) lejos de ser la de un conspirador o inductor de pronunciamientos, fue la de aceptar y defender la Constitución de 1869 y coadyuvar a la consolidación de la Monarquía democrática de D. Amadeo de Saboya mediante el apoyo parla. mentario a la opción consenvadora del régimen, la de Serrano y Sagasta. Sólo cuando el gobiemo radical de Ruiz Zorrilla, con la ayuda de los antisistema - republicanos, carlistas y moderados-apartó del régimen a los constitucionales en el verano de 1872, Cánovas, al igual que muchos de estos uitimos, creyó imposible la Monarquía de Amadeo I para asentar la libertad en España. A partir de entonces se dedico a organizar el alfonsismo y a extender la opinión favorable a la Restauración liberal y civil en D. Alfonso de Borbón.

Palabras clave. Siglo xix, Monarquía democrática, Sexenio Revolucionario, Reinado de Amadeo I, partidos políticos, liberallsmo conservador, Alfonso XII, Cánovas.

ARSTRACT: Cánovas's attitude during the Revolutionary Six Year Period (1868-1874), far away from being that of a conspirator or insurrection inductor, was to accept and defend of the Constitution of 1869 and cooperate for the consolidation of Amadeo de Saboya's democratic Monarchy by means of the Parliament's support to the Serrano's and Sagasta's conservatice choice. Only when Ruiz Zorrilla's radical goverment, with the assistance of the so called antisystem - republicans, carlists and moderate- took aside constitutionalists from the regime in summer 1872, Canovas, like many of these latter, thougt about the impossibility of Amadeo I's monarchy for the settling of freedom in Spain. From that moment on he devoted to organize the policy supporting the Alfonso's and to expand a favourable opinion to the liberal and civil Restoration in the person of D. Alfonso de Borbon.

KEY WORDS: 19th century, Democratic Monarchy, Revolutionary Six Year Pertod, Relgn of Amadeo I, political parties, conservative liberalism, Alfonso XII, Cánovas.

Hispania, LVII/3, núm. 197 (1997) \107-1129 


\section{INTRODUCCION}

Las incógnitas que surgen cuando se estudia la figura de Cánovas del Castillo, su papel y postura política en el Sexenio Revolucionario, han dividido a gran parte de los historiadores. La idea general y más extendida es la de la constante conspiración, o trabajo silencioso, en pos de la Restauración borbónica. Sin embargo, cuesta creer que un político de tan fácil adaptación como Cánovas, de tanto respeto a la legalidad vigente fuera cual fuera mientras constituyera fuente de orden, se mantuviera alejado del centro de poder estando tan cerca de él.

¿Hasta qué punto participó Cánovas en el nuevo régimen? ¿Qué ideas guiaban sus actuaciones a lo largo de aquel período? ¿Cuáles fueron sus posturas políticas ante los diferentes gobiernos durante el reinado de Amadeo? ¿Qué tareas realizó como parlamentario? ¿Qué grupo organizó en el Congreso? ¿Cómo se constituyó en jefe del alfonsismo?

La respuesta más común a estas preguntas apunta a su rechazo a la monarquía amadeísta, a la poca importancia de la vida parlamentaria de Cánovas frente a su actuación fuera del Congreso, todo ello basado en una vaguedad de datos y comentarios imprecisos sobre su relación con el ala más moderada de la revolución de septiembre. El Cánovas más conocido es el de la Restauración, sin embargo, falta conocer con un poco más de profundidad el Cánovas del Sexenio Revolucionario. Este es el objetivo que nos hemos marcado en este trabajo.

\section{CÁNOVAS EN LAS CORTES CONSTITUYENTES}

\section{Los primeros meses de la Revolución}

En septiembre de 1868 culminó el movimiento revolucionario que se venía preparando desde tres años atrás. Cánovas, que siempre se sintió unionista ', no participó en la Revolución a pesar de que había firmado la carta de protesta de los diputados ante la no convocatoria de Cortes en 1866 -lo que le supuso el destierro--, y la crítica que desde su escano hizo a los últimos gobiernos moderados.

Cánovas fue llamado por el Gobierno Provisional de Prim y Serrano, en octubre de 1868, para desempeñar el cargo de presidente de una de las sec-

\footnotetext{
1 Los unionistas se hallaban divididos entre aquellos que apoyaban el régimen isabelino desde una postura crítica hacia el papel político que desarrollaba la Reina, y los que, por esta razón, trabajaban para su desmantelamiento. Los primeros eran comandados por O'Donnell —que muere el 5 de noviembre de 1867 - y los segundos por Serrano. Cánovas se contaba entre los críticos desde la Vicalvarada de 1854.

Hispania, LVI]/3, núm. 197 (1997) 1107-1129
} 
ciones del Consejo de Estado ${ }^{2}$. No aceptó, y prefirió mantenerse desligado de todo compromiso ${ }^{3}$.

Permaneció Cánovas entonces a la espera de comprobar quién, finalmente, se hacía con el poder, ya que la coalición revolucionaria carecía de un proyecto político claro que llevar a la práctica, y se estaba produciendo un grave desorden debido a que las Juntas provinciales se habian erigido en auténticos gobiernos de elección popular, y además el pueblo estaba armado y liderado por los republicanos.

Las elecciones del 15 al 18 de enero de 1869 dieron la victoria a la coalición monárquico-democrática formada por progresistas, unionistas y demócratas. Los gubernamentales obtuvieron 236 actas, mientras que la oposición antisistema - republicanos y carlistas- consiguieron 85 y 20 , respectivamente. Esta mayoría monárquica aseguraba la formación de un régimen constitucional-parlamentario de derechos y libertades, con sufragio universal, y con un rey como poder moderador. Los vencedores ya estaban definidos. Cánovas, que había conseguido un acta de diputado ${ }^{4}$, formó, junto a seis parlamentarios, el grupo liberal-conservador ${ }^{5}$.

\section{Las ideas liberal-conservadoras}

Cánovas, más allá del enfoque que hace de él un conspirador perpetuo ${ }^{6}$, aceptó la legalidad y votó a favor de la Constitución de 1869. La posición polí-

2 Lema, Marqués de, Cánovas o el hombre de Estado, Madrid, Espasa-Calpe, 1931, pág. 64. Para Nido este rechazo demostraba su postura «antirrevolucionaria y borbónica». NIDO Y SEGALERVA, Juan del, Historia política y parlamentaria del Excmo. Sr. D. Antonio Cánovas del Castillo. Madrid, 1914, pág. 294.

3 Diario de las Sesiones de las Cortes Constituyentes [en adelante DSCC], 6 de junio de 1870, núm. 299, págs. 8621-8629, 8633-35 y 8639-41. LópEz GARRIDO, recoge en su libro Antonio Cánovas del Castillo. Discursos parlamentarios, publicado por el Centro de Estudios Constitucionales en 1987, tan sólo cuatro discursos del período del Sexenio. En nuestro trabajo recogemos todas las intervenciones, actividades y discursos parlamentarios de Cánovas y de su grupo en las Cortes del Sexenio, en su contexto y relación con los otros líderes y grupos políticos.

4 En estas primeras elecciones al Congreso fueron tres las candidaturas: monárquica - la coalición unionista, demócrata y progresista-, republicana y absolutista. Cánovas se situó en el pritner grupo, entre los diputados unionistas. La Época, 23 de enero de 1869.

5 Joaquín Vázquez de Puga, Luis Estrada, José de Elduayen, Saturnino Álvarez Bugallal, Manuel Quiroga Vázquez y Francisco Silvela -este último fue admitido como diputado por Ávila el 8 de febrero de 1870-. Don Juan Valera denominaba a Cánovas, ujefe de los unionistas alfonsinos», en «Revista política interior», Revista de España, núm. 55, junio de 1870, pág. 473.

6 Yllan Calderón, Esperanza, Cánovas del Castillo. Entre la Historia y la politica, CEC, Madrid, 1985, escribe, entre otras conclusiones parecidas: «bo que interesa poner de manifiesto, en relación a la citada opción canovista, son precisamente estos antecedentes de su biografia política, como artifice de la Restauración, en cuyos orígenes hay que reconocer una gestación conspiratoria que, por un lado, hacía inevitable el fracaso del Sexenio y, por otro, haria posible el pronunciamiento militar que inaugura el sistema canovista». Sobre el carácter «conspirador permanente» de Cánovas y su «anuencia con el golpe militan volveremos más adelante.

Hispenia. LVIl/3, nüm. 197 (1997) 1107-1129 
tica que adoptó en el periodo constituyente no fue muy diferente a la de otros grupos de la oposición, e incluso, cumplió con la función clásica parlamentaria de crítica y control al Ejecutivo, unida a la presentación de proposiciones alternativas a la dispuesto por la comisión constituyente. Es decir, en lugar de una disposición negativa o de incompatibilidad con el nuevo régimen, su actitud fue crítica, como corresponde a toda oposición parlamentaria, con aceptación de algunos de los términos propuestos por el Gobierno.

Fue en este período en el que expuso sus principios políticos referidos al nuevo régimen, y a partir de los cuales, según luego repetirá en múltiples ocasiones en el Congreso, guiará su actuación ${ }^{7}$. Criticó la extensión de los derechos y libertades establecidos en el proyecto de constitución, no en su naturaleza, sino en el sentido de que no se correspondían con la fuerza del Estado existente. Hacía falta un Estado fuerte, contrapeso de los derechos y libertades, cuya fortaleza debía ir en proporción a los derechos que estableciera la Constitución política ${ }^{8}$. Para Cánovas, el Estado, como garante del orden social, tenía el deber de defender los derechos constitucionales, de los cuales el que él creía fundamental era el de propiedad y herencia, al que consideraba principio de continuidad y sucesión ${ }^{9}$. La forma de gobierno más perfecta para asegurar tal principio y la relación entre los derechos y las libertades, era la Monarquía hereditaria ${ }^{10}$. En España, decía Cánovas, era necesaria una monarquía de ancha base, que se reconociera anterior a cualquier constitución, con las facultades suficientes como para mantener el orden y consolidar la libertad ${ }^{11}$, y que diera, por ende, tranquilidad a las clases conservadoras para que activaran la economía del país. En cuanto a las facultades de la Corona, discrepaba sólo en que el texto constitucional no mantenía su prerrogativa de la iniciativa legislativa a través de sus ministros, ni podía nombrar senadores ya que la cámara alta era totalmente electiva.

7 DSCC, 8 de abril de 1869, núm. 44, págs. 926-938. La Época del 9 de abril comentaba así ef discurso: «El partido moderado está dentro de la Cámara —repetían ayer algunas voces después de cesar la del Sr. Cánovas del Castillo. ¡Error! (...) Eran los partidos medios en general, era la clase media, elemento indispensable a la libertad, era el sistema constitucional tal cual la porción más culta y libre de la Europa lo practica, era la libertad misma, la armonía entre el progreso y el orden, entre el individuo y la sociedad lo que el ministro de 1864, el compañero del general $O^{\circ}$ Donnell en 1866 defendia.»

8 Ibid., y Cánovas del CAStillo, A., «Discurso acerca de la Internacional», en Problemas Contemporáneos, Colección de Escritores Castellanos, núm. 17, vol.I, pág. 386. Discurso II en el Ateneo, «Pesimismo y optimismo en relación con los problemas de la época actual» (25 de noviembre de 1871), en OO.CC., I, Fundación Cánovas del Castillo, Madrid, 1981, pág. 72.

9 «Discurso acerca de la Internacional», ob. cit., pág. 408-410 y $418-421$. Discurso il en el Ateneo, ob. cit., pág. 73-4.

10 DSCC, 8 de abril de 1869, núm. 44, págs. 926-38; DSCC, 21 de diciembre de 1870, núm. 322 , págs. $9291-9294,9298-9301,9303$ y 9304 .

II lbidem; DSCC, 14 de diciembre de 1869, núm. 182, págs. 4715-25; y 6 de junio đe 1870; Introducción a La oposición liberal-conservadora en las Cortes constituyentes de 1869 a 1871 , Madrid, Rivadeneyra, 1871, págs. V y XIV; Cánovas del Castillo, A., Carta de despedida a los electores de Cieza y Yecla, Madrid, Rivadeneyra, 1872, págs. 4 y 5.

Hisponia, LVIJ/3, núm. 197 (1997) 1107-1129 
Frente a la Monarquía doctrinaria, la nueva sería democrática, es decir, creada por los representantes del pueblo, sin que por ello se privara de la soberanía a las generaciones futuras, ya que sus representantes podrían legalmente cambiar la forma de gobierno sin que el Rey tuviera poder constitucional alguno, ni de disolución, ni de negativa de sanción, sobre las Cortes reunidas con ese fin. El rey de la Constitución de 1869 mantenía la capacidad para aprobar, diferir o desaprobar las decisiones de los ministros, dando, suspendiendo o negando la firma de las disposiciones que éstos últimos le presentaran; igualmente nombraba al Presidente del Consejo, acogiéndose, claro está, a las reglas del parlamentarismo. Lo principal era que el rey se constituía en poder moderador, en árbitro de los conflictos entre los poderes del Estado, que dirime las luchas entre los partidos según las reglas constitucionales ${ }^{12}$

La Unión Liberal y los progresistas de Sagasta, que formaron el partido constitucional a finales de 1872, fueron los únicos decididamente monárquicos durante el reinado de Amadeo I. Los demócratas - parte integrante y determinante del partido radical que componían junto a los progresistas de Ruiz Zorrilla-, si bien habían definido junto a los otros componentes de la coalición revolucionaria las facultades de la Corona en la monarquía democrática, entendían ésta como forma de gobierno accidental, e incluso provisional, para una España no preparada para la República ${ }^{13}$. Además, los radicales no dudaron en unirse parlamentariamente a los partidos antisistema para derribar Gobiernos del régimen -el voto de censura del 13 de noviembre de $1871-$ y electoralmente, a esos mismos partidos en las elecciones de abril de 1872, o emprender campañas de prensa contra Amadeo I cuando éste no llamó a Ruiz Zorrilla para formar Gobierno en las crisis de enero y junio de ese mismo año. Por otro lado, los republicanos extendieron su organización por toda España, y el federalismo pactista y socialista pimargalliano fue aceptado por la mayoría del partido republicano; ideas que para el político conservador suponían una violación del principio de continuidad social, un atentado a la institución monárquica y una imposible coexistencia del orden con la libertad ${ }^{14}$. Por tanto, la conservación de la Monarquía fue la cuestión básica para que Cánovas y el grupo liberal-conservador no solamente votaran a favor de la Constitución sino para que prestaran su apoyo a los gobiernos más templados de la revolución de septiembre.

El argumento del mantenimiento del orden en libertad, del respeto a la institución monárquica, fue la base de sus reiterados ofrecimientos de apoyo al

12 Calero, Antonio María, Monarquía y democracia en las Cortes de 1869, C.E.C., Madrid, 1987, págs. XVI1 $\times X X$; «Los precursores de la monarquía democrática», en La España de la Restauración, ed. al cuidado de J. L.García Delgado, Madrid, Siglo XXI, 1985, págs. 21-32; en ambas obras, el profesor Calero expuso detalladamente el proyecto de monarquía democrática que la coalición revolucionaria articuló en las Cortes Constituyentes de 1869.

13 CALERO, Monarquia y democracia..., ob. cit., pág. XXIII.

14 DSCC, 8 de abril de 1869 , núm. 44, págs. 926-38; DSCC, 21 de diciembre de 1870 , núm. 322, págs. 9291 y ss.

Hi.spania, LVII/3, nủm. 197 (1997) 1107-1129 
Gobierno Provisional de Prim, Serrano y Sagasta - que luego veremos con más claridad cuando se trate de ministerios netamente conservadores durante el reinado de don Amadeo-y una posición política que le alejó de posturas antisistema, como las de los moderados, republicanos y carlistas, y que le situó como parte integrante del régimen.

Su candidato al trono fue el príncipe Alfonso, pero con la trascendencia de ser la postulación de una forma de gobierno o un candidato, una de las banderas comunes de todos los partidos. Lo que distinguió al grupo liberal-conservador, es que, una vez elegido Amadeo de Saboya, desistió públicamente de cualquier crítica, y acepto, sin rodeos, el texto constitucional. Esto les convirtió en una opción de gobierno, al no poder ser acusados de encontrarse fuera de la Constitución ${ }^{15}$, al conectar con las ideas de la fracción derecha del bloque monárquico-democrático y ofrecer, en reiteradas ocasiones, su apoyo. Fue en este sentido en el que Cánovas del Castillo habló de la formación de un gran partido monárquico.

Las sucesivas crisis de Gobierno entre junio y diciembre de 1869 empujaron fuera del Ejecutivo a los unionistas en favor de los demócratas, y revelaron que no existía un Gobierno fuerte. Las tres fracciones gubernamentales carecían de un mismo proyecto político, las diferencias entre los grupos seguían siendo de enorme importancia -lo que suponía que el partido monárquico-democrático era una ficción-, de lo cual resultaba que la propia supervivencia del régimen revolucionario iba más allá de establecer un rey con poderes constitucionalmente limitados.

El problema de la formación de un partido que se erigiera como representante único de la Revolución, que permitiera la consolidación y desenvolvimiento del nuevo régimen, fue el problema irresuelto que dio al traste con la experiencia monárquico-parlamentaria. Cánovas del Castillo, desde los bancos de la minoría, ofreció, en repetidas ocasiones, la formación de un gran partido monárquico.

La necesaria cuestión que surge en este momento es el por qué no formó un grupo con los moderados, que contaban con el apoyo de Isabel II. Los moderados, que tuvieron su primera reunión de reorganización en febrero de 1870 , dirigidos por Catalina, Belda y Moyano ${ }^{16}$, tenían como bandera la Constitución de 1845 y el modelo de los gobiernos de Narváez. Pero ya no contaban con el favor de los generales antaño adictos, toda vez que Cheste habia dimitido de su cargo de presidente del partido isabelino, y, González Brabo, al igual que el político Nocedal, se había pasado al bando carlista. El grupo moderado suponía, entonces, la vuelta a una situación cuya naturaleza había

is Es significativo el voto en blanco en la elección del Rey, ya que les revelaba como una opción enteramente abierta a cualquier tipo de posibilidad dentro del régimen constitucional, o para lograr una posición ventajosa ante las clases conservadoras que añoraban un Borbón en el trono, como los moderados supervivientes, incluso frente a la misma Corona, porque Cánovas no queria una restauración isabelina.

16 Fabié, Antonio María: Cánovas del Castillo, Gustavo Gili Editor, Barcelona, 1928, pág. 76. El autor es hijo del Fabié canovista del Sexenio.

Hispania, LVlt/3, núm. 197 (1997) 1107-1129 
engendrado la misma revolución, y cuya cabeza, la exiliada Reina Isabel, era violentamente denostada por la mayoría de los españoles, y, por tanto, se había convertido en imposible vía de retorno de los Borbones ${ }^{17}$.

El problema de la falta de autoridad, no ya en un sistema político consolidado, sino especialmente y en lo que viene al caso, en una situación política revolucionaria, puede dar lugar a guerras civiles o a dictaduras militares. Para Cánovas, si los artífices de la Revolución no eran capaces de aglutinarse bajo un mismo proyecto que asegurara la autoridad y con ella la estabilidad poljtica, era inevitable el advenimiento de la República federal, y por tanto del gobierno de lo que él llamaba muchedumbre ignorante. $\mathrm{El}$ acceso del pueblo al poder mediante el sufragio, hacía temer, no sólo a él, que las ideas socialistas de algunos federales se transformaran en poder político.

De esta forma, en plena organización del partido republicano federal, entre mayo y julio de 1869 , fue cuando Cánovas reiteró de una forma clara que el Gobiemo podía contar con su voto y total apoyo. El argumento canovista era el de que, estando pendiente el desarrollo de la Constitución a través de leyes orgánicas, apoyaría al Gobierno cuando corrigiese los abusos previsibles en el uso de los derechos y libertades con tales leyes. Cánovas se mostraba dispuesto a transigir con una Monarquía que, aunque no estuviera fundada en sus principios, aunase el orden y la libertad, y mientras tanto, no se negaba a realizar transacciones ${ }^{18}$.

Los Pactos regionales que los republicanos comenzaron con el de Tortosa el 18 de mayo y que culminaron el 30 de julio con el Pacto Nacional en Madrid, confirieron a ese partido la posibilidad de levantar en armas a cerca de 40.000 Voluntarios de la libertad coordinados por el Consejo Federal, y poner en serio riesgo el desarrollo de la Monarquía. Además, las bases de los acuerdos contaban con el "derecho de insurrección" si el Gobierno menoscababa los derechos del Título I de la Constitución, especialmente las garantías individuales frente a posibles arbitrariedades de la autoridad, la libertad de imprenta y los derechos de asociación, reunión y de petición individual y colectiva ${ }^{19}$.

El restablecimiento de la ley de orden público del 17 de abril de 1821, mediante un decreto precedente de instrucciones a los gobernadores civiles con motjvo del levantamiento carlista en julio de 1869-, y las medidas para restablecer el orden que siguieron al asesinato del gobernador civil interino de Tarragona a manos de los republicanos el 20 de septiembre, adelantaron los planes insurreccionales de aquellos, que utilizaron los acuerdos de los Pactos. Así comenz 6 , a finales de septiembre de 1869 , la insurrección federal, que daría sus últimos coletazos en Andalucía al terminar el año. Fúe justamente entonces cuando Cánovas propuso la unión de las tendencias monárquicas en una gran

17 Era un proyecto acabado; en palabras de Fabié refiriéndose a la reunión de febrero de 1870 : «los generales, deudos y amigos de Narváez se excusaron con diferentes pretextos y los elementos jóvenes de la derecha contestaron que no querían abrazarse a un cadáver». Ibid.

18 DSCC, 14 de julio de 1869 , núm. 126, págs. 3727-373] y 3733-4.

19 Nótese que los republicanos mantuvieron el principio de la «revolución legal» que los progresistas habian defendido desde sus orígenes.

Hispania, LVII/3, núm. 197 (1997) 1107-1129 
coalicion que representara a las clases conservadores para asegurar el orden, y que mantuviera la monarquía que constitucionalmente el parlamento iba a ele- gir. Un gran partido monárquico de gobierno que acabara con las rivalidades crecientes dentro del grupo septembrino, y que pusiera coto a la fortaleza popular que el partido republicano iba cobrando. Esa misma coalición volverá a reclamarla con motivo de la discusión de la ley de elección de rey en junio de 1870 . Se trataba, en definitiva, de lograr una monarquía de amplia base, que no se apoyara solamente en un partido o fracción, que consiguiera el beneplácito de agran parte de la opinión monárquica", con la "suficiente anchura para atraer y consolidar el orden con la libertad». Cánovas dejó sentado en ese momento que, a pesar de que nunca excluiría al príncipe Alfonso, si el Gobierno conseguía otro candidato que realizara tales principios, lo apoyaría totalmente ${ }^{20}$.

\section{CÁNOVAS EN EL REINADO DE AMADEO 1}

El grupo liberal-conservador de Cánovas publicó a comienzos de 1871 una recopilación de los discursos parlamentarios de sus integrantes; en su introducción hacía balance de tres años de Revolución, y exponía sus pros y sus contras. El grupo aceptaba lo que comulgaba con sus principios liberales y con todo aquello que fuera conservador; mostraba una actitud expectante ante Amadeo, y llamaba, finalmente, a la unión de las fracciones monárquicas constitucionales, pero ya solamente para acuerdos concretos de gobierno ${ }^{21}$.

Muerto Prim el 30 de diciembre de 1870, y tras un Gobierno interino del brigadier Topete, el 3 de enero de 1871 Amadeo de Saboya juró la Constitución. El General Serrano formó un Ministerio de conciliación, en palabras del propio duque de la Torre, formado por unionistas, progresistas y demócratas ${ }^{22}$.

20 DSCC, 14 de diciembre de 1869, núm. 182, págs. 4715-25; y 6 de junio de 1870, núm. 299, págs. 8621-8641. En la sesión del 15 de diciembre el diputado progresista Gabriel Rodriguez preguntó a Cánovas sobre el sentido de su Ilamamiento a la formación de un partido conservador, instándole a que esperara a que el proceso constituyente terminara. El hecho de la connivencia del grupo canovista con el elemento conservador de la mayoría gubernamental presenta numerosas referencias en los debates de las Cortes.

21 «Monárquicos constitucionales antes que nada los que publican hoy este libro, de ningún par* tido monárquico constitucional quieren, por lo mismo, declararse divorciados para siempre. Lejos de eso, laméntanse de no tener autoridad bastante para predicar a todos con éxito que, en lugar de abrir entre sí abismos, pronunciando contrapuestos jamases, estudien constantemente, y según se vayan presentando los sucesos, el mejor modo de llegar a un prudente concierto; concierto en que estriba toda la esperanza de buen porvenir que le reste a esta pobre patria; concierto no total y minucioso naturalmente, sino limitado a aquellos puntos cardinales que deben ser fijos y permanentes en nuestro sistema políticon. La oposición liberal-conservadora en las Cortes Constituyentes de 1869 a 1871, Madrid, Rivadeneyra, 1871, págs. XVI-XVII.

22 En las elecciones de marzo de 1871 la Coalición obtuvo 235 actas, frente a republicanos y carlistas -que se presentaron juntos a las votaciones, ya que las tomaron como un plebiscito sobre Amadeo :-, los cuales consiguieron 52 y 51 actas, respectivamente. Los moderados alcanzaron, por su parte, $18 \mathrm{y}$, los liberal-conservadores de Cánovas, 9 'actas.

Hispania, LVI1/3, num. 197 (1997) 1107-1129 
En su programa de gobierno, expuesto en el Discurso de la Corona, incidía en dos cuestiones: Hacienda y Ultramar. Cánovas y su grupo apoyaron el plan económico del ministro demócrata Moret y la política colonial del unionista Ayala, pues deseaban el mantenimiento de la Coalición de septiembre como instrumento de estabilidad política ${ }^{23}$. Esta actitud de Cánovas se hizo mucho más evidente con motivo de la propuesta de Sagasta, ministro de la Gobernacion, de reformar el Reglamento de las Cortes de 1854, el cual regía provisionalmente. Dicha proposición significaba la posibilidad de modificar la Constitución sin que tales proyectos pasaran por las secciones ${ }^{24}$, es decir, que el Gobierno los presentara al Congreso y éste, tras un debate, los votara.

La idea de una reforma constitucional en sentido conservador consistente en limitar los derechos del Título I, ya expuesta por Cánovas en la discusión del proyecto de Constitución, la intentó llevar a la práctica el General Serrano en tres ocasiones durante el reinado de Amadeo I: en ésta reforma del Reglamento; en las condiciones que le expuso al Rey para la aceptación de la jefatura del Gabinete en el verano de 1871 y, por último, en la petición de sanción del decreto de suspensión de las garantías constitucionales de junio de $\mathbf{1 8 7 2}$.

El dictamen de la comisión parlamentaria fue favorable a la reforma del Reglamento de 1854 y, tras una discusión que duró 4 días, los grupos parlamentarios presentaron sus enmiendas. Los liberal-conservadores de Cánovas, coincidentes con la propuesta, presentaron una corrección, realmente un añadido, para que el artículo 33, el referido a la Monarquía como forma de gobiemo de España, quedara excluido de toda reforma que no pasara por las secciones del Congreso. Álvarez Bugallal defendió esta enmienda, en un discurso donde era perfectamente visible la mano de Cánovas. Alegó en él su posible utilización por parte de republicanos o carlistas para cambiar de manera legal la forma de gobierno. Afirmó la necesidad de un principio de estabilidad, que fuera inmutable, alrededor del cual se desarrollara el sistema político y permitiera la flexibilidad necesaria para el progreso dentro del orden legal. Bugallal terminó su discurso prometiendo el apoyo de su grupo al general Serrano si excluía la posibilidad de variar el artículo referido a la forma monárquica ${ }^{25}$.

La postura de Serrano y Sagasta de mantener la Coalición de septiembre para consolidar las instituciones, que era parlamentariamente apoyada por

\footnotetext{
23 Diario de las Sesiones del Congreso de los Diputados [en adelante DSC], 26 de mayo de 1871, núm. 44, págs. 1195-1201; y 4 de julio de 1871, núm. 86, págs. 2249-2250.

24 Las secciones se formaban por sorteo al comienzo de cada mes entre los diputados, con to que la Cámara se dividía en siete grupos. Posteriormente, las secciones designaban a uno de sus miembros para que formara parte de las comisiones demandadas por el proceso legislativo, por lo que éstas estaban siempre formadas por siete diputados. La comisión elaboraba un dictamen que luego era discutido en la Cámara. Cánovas formaba parte de la de Corrección de estilo. DSC, 19 de mayo de 1871, núm. 39.

25 DSC, 25 y 26 de mayo de 1871 , núm. 43 y 44 , págs. 1182 y $1195-1201$, respectivamente. Finalmente se exceptuó del dictamen toda reforma de la Constitución que no contara con las secciones, es decir, con el previo examen y apoyo de la Cámara.
}

Hispania, LVIl/3, núm. 197 (1997) 3107-1129 
Cánovas, se vino abajo por la decisión de Ruiz Zorrilla, líder de la izquierda del progresismo desde la muerte de Prim, de dividir la Coalición y formar el partido radical, idea compartida por Martos y Rivero, jefes de los demócratas. Por estas circunstancias, el Gobierno entró en una larga crisis. La fracción derecha de la Revolución, los unionistas de Serrano y los progresistas templados de Sagasta, no se decidían aún por la separación. Cánovas, consciente de que si sólo se formaba el partido radical del régimen, éste sería dominado por ésta opción, alentó en el Congreso de los Diputados a Sagasta y a sus "antiguos amigos", los unionistas, a que se desligaran de sus pactos con la fracción izquierda y formaran el grupo conservador ${ }^{26}$. Prometía para esto el mismo apoyo que él y su grupo les habían venido dando.

Sagasta, ante la posible formación de un nuevo gobierno integrado sólo por elementos moderados de la Coalición, consultó a su partido sobre el apoyo que éste obtendría en el Congreso, pero comprobó que la mayor parte del progresismo era zorrillista. En consecuencia, el 24 de julio de 1871, Serrano dimitió y Ruiz Zorrilla presentó su Gobierno. En el debate de presentación del Gabinete, el unionista Augusto Ulloa explicó que no se había formado un Ministerio conservador porque aún no estaba organizado tal partido, y finalizó haciendo un llamamiento a los grupos afines para que lo formaran. Ante ésta situación, el canovista Álvarez Bugallal abogó por una suspension de las sesiones de las Cortes ${ }^{27}$.

En dos meses la opción conservadora se había formado, y además con solidez, pues, el 3 de octubre de 1871 se produjo la votación para elegir al Presidente del Congreso en la que Becerra, candidato radical, fue derrotado en doble votación por Sagasta ${ }^{28}$. Ruiz Zorrilla, comprendió que había perdido el apoyo de la mayoría de la Cámara y, habiendo agotado la posibilidad de suspensión de Cortes, decidió dimitir. La votación no fue nominal, pero caben pocas dudas sobre los votos del grupo liberal-conservador de Cánovas en esta ocasión. Se hace difícil pensar que se ausentara del Congreso en una crisis ministerial que podía tener como resultado el fortalecimiento de la tendencia radical -de cuya voluntad para afianzar el régimen monárquico de la Constitución de 1869 Cánovas desconfiaba--, o por el contrario, el establecimiento de un Gobierno conservador más cercano a sus ideas. Resulta todavía más improbable que votara a favor del candidato de Ruiz Zorrilla o que, finalmente, se abstuviera, máxime cuando en pasadas sesiones hab́a prometido su apoyo a un ministerio conservador, como hemos visto en repetidas ocasiones.

\footnotetext{
26 Esto mismo reclamaria pocos meses después el Rey Amadeo en el famoso «papelito». MAS HESSE, Margarita, y TRONCOSO RAMÓN, Rafael, «La práctica del poder moderador durante el reinado de Amadeo I de Saboyas, Revista de Estudios Políticos, núm. 55, enero-marzo de 1987, págs. 237 271. Los autores resumen y explican, de una forma excelente, las crisis de gobiemo y el papel de Amadeo I como poder moderador, para, a través de ellas, analizar el fracaso del sistema de partidos durante el Sexenio.

27 DSC, 25 de julio de 1871 , núm. 110, págs. 2852-2877.

28 En la primera votación hubo 110 sufragios a favor de Sagasta y 109 para Rivero, con 17 en blanco. Al no conseguir mayoría absoluta se hizo una segunda votación, consiguiendo esta vez Sagasta 123 y Rivero 113 sufragios.

Hispania, LV1]/3, núm. 197 (1997) 1107-1129
} 
A partir de entonces, la actitud política de Cánovas y de su grupo será de total apoyo a la fracción conservadora de Serrano y Sagasta. Durante el Ministerio Malcampo que progresistas moderados y unionistas formaron tras la dimisión de Ruiz Zorrilla, Cánovas apoyó la resolución del Gabinete de declarar ilegal a la Asociación Internacional de Trabajadores, asunto que cobró importancia porque el Gobierno la convirtió en cuestión de confianza ${ }^{29}$.Igual disposición mantuvo cuando los radicales presentaron el 13 de noviembre de 1871 una moción de censura al Gabinete, o cuando los carlistas presentaron una proposición incidental sobre libertad de fundar y conservar las instituciones y comunidades religiosas, es decir, el restablecimiento de aquellas que disposiciones revolucionarias habían declarado abolidas. La proposición carlista añadía que esta ley fuera discutida y aprobada inmediatamente, saltándose el dictamen de una comisión parlamentaria, el debate en el Senado y la sanción de la Corona. Esta propuesta anticonstitucional fue defendida por carlistas, republicanos y radicales con el único ánimo de derribar al Gobierno. Cánovas, Elduayen y Álvarez Bugallal defendieron la postura del Ministerio de seguir los trámites legales. A pesar de este apoyo la oposición venció, en una sesión que duró diecisiete horas, por 174 votos frente a $118^{30}$. Derrotado Malcampo, fue sustituido en la Presidencia del Gabinete por su jefe de filas, Sagasta.

En el discurso-programa del nuevo Gobierno se vio la decisión definitiva de constituir un partido conservador, pues desaparecia toda invocación a antiguas afinidades progresistas. Presentó al brigadier Topete como enlace con las tendencias cercanas, en clara referencia a la canovista, a la que invitó a una unión que calificó de indispensable para la continuidad del Ministerio. Sin embargo, la oposición, formada por carlistas, republicanos y radicales, propuso alargar la sesión para discutir la crisis ministerial anterior y el programa de gobierno presentado. Sagasta se negó e hizo de ello cuestión de confianza. En la votación de ésta, a pesar del apoyo del grupo liberal de Cánovas, los conservadores fueron derrotados $3 !$.

29 Los días más importantes del debate fueron el 18 y 26 de octubre, y el 3,6 y 10 de noviembre de 1871 , núm. 121, 128, 134, 136 y 139, respectivamente. También puede verse CÁNOVAS DEL CASTILlo, Antonio, «Discurso acerca de la internacional», Problemas Contemporáneos, ob. cit. Los desiguales y tardíos discursos de los republicanos para congraciarse con la A.IT. española -organización que ya en sus albores, en junio de 1870 en Barcelona, renegó del partido republicano por "poco socialista», LoREnzo, Anselmo, El proletariado militante, Madrid, Alianza, 1974, págs. 101 y 118-123; ARbeloA, V. M., I Congreso Obremo Español. Barcelona, 1870, Mađrid, ZYX, 1972, con atención a las intervenciones de sus dirigentes, Lorenzo y González Morago, págs. 2679 y 272-6, Nemrau, Max, Miguel Bakunin, la Internacional y la Alianza en España (1868-1873), La Piqueta, Madrid, 1977; los recoge Garrido, Fernando, Historia de las clases trabajadoras, vol. 4, Madrid, Ed.Zero, 1973. Sobre cómo se vefa en España a la A.I.T., especialmente a raíz de la Comusa de París, Álvarez Junco, José, La Comuna en España, Madrid, Sigjo XXI, 1971.

30 Publicado el resultado de la votación, Malcampo leyó el decreto de suspensión fimado por el Rey y fechado el dia anterior. Conscientes los conservadores de la Revolución que iban a ser derrotados, Romero Robledo estuvo improvisando un discurso durante el tiempo suficiente como para que el Presidente del Consejo consiguiera la firrma de Amadeo I. DSC, 17 de noviembre de 1871, núm. 146.

31 DSC, 22 de enero de 1871 , núm. 1.

Hispania, LVII/3, nüm, 197 (1997) 1107-1129 
El 24 de enero de 1872 se abrió la sesión en el Congreso con el rumor de que Sagasta llevaba en la cartera el decreto de disolución ${ }^{32}$, con el objeto de convocar elecciones y fabricarse una mayoría sólida con la que gobernar.

Cánovas defendió, en un discurso gubernamental, la prerrogativa regia de disolución. Acepto la invitación de Martos de formar parte del partido conservador que intentaba sustentar al Gobiemo. Reconocio haber luchado contra la Constitución cuando era proyecto, pero ahora se confesaba leal a la misma, estar dentro de ella y querer contribuir a su buena práctica. Se decía inmerso en un deber: hacer posibles el orden y la libertad con la Constitución de 1869. Definió su actitud, que no sería de testigo, sino que coadyuvaría al éxito del Ministerio conservador, porque «todos los elementos conservadores que yo represente estarán al lado del Gobierno. Diré más, y es, que con Gobiernos como éste, que con políticas que propendan al orden aunque dentro de la legalidad vigente, que con una Cámara que propenda clara y abiertamente al orden, muchos elementos conservadores, aquellos que yo entiendo que represento, podrán estar al lado del Gobierno, a la vez que no lo estarian nunca si alcanzara el poder la política representada por el tumulto de esta tarde., ${ }^{33}$

Cuando se abrieron las Cortes ${ }^{34}$, el Rey Amadeo I pronunció un discurso de apertura que era el programa del Ministerio Sagasta. En él hablaba de reformar los defectos que se encontraran en los derechos constitucionales para su mejor ejercicio, corregir la ley de matrimonio civil, comenzar la reforma del Código Penal, y elaborar una ley de enjuiciamiento criminal que contuviera el Jurado ${ }^{35}$. El giro conservador y la coincidencia con algunas de las ideas expresadas por Cánovas en el Congreso eran evidentes. Incluso se adoptó el Reglamento de 1847, el cual no contemplaba la discusión de las actas $^{36}$. La Mesa de la Cámara fue elegida entre elementos conservadores, así como la comisión auxiliar de actas. En ambos órganos quedó claro el ascenso de uno de los integrantes del grupo liberal-conservador de Cánovas, Elduayen, ya que fue elegido Vicepresidente del Congreso y Presidente de la Comisión de Actas, y, más tarde presidiría también la Comisión de Presupuestos.

32 Ply Margall, Francisco, El reinado de Amadeo de Saboya y la República de 1873, Seminarios y Ediciones, Madrid, 1970, pág. 68. En el debate, muy enconado, las interrupciones fueron constantes y la referencia al rumor de la existencia del decreto de disolución provocó el deseo, en todos los diputados, de querer exponer su situación ante el Gobierno.

33 DSC, 24 de enero de 1872, núm. 2, págs. 64-67.

34 Las elecciones se celebraron en abril de 1872 , consiguiendo los conservadores de Sagasta y Serrano 236 actas, frente a lo que se llamó coalición anticonstitucional de radicales, republicanos y carlistas, que, obtuvieron 42, 52 y 48, respectivamente. Esta extraña unión, flaco favor a la Monarquia amadeista, fue alentada por Ruiz Zorrilla —el acuerdo se firmó en su casa- y su pacto consistía en que, dado que los distritos eran uninominales según la ley promulgada durante el progresista Gobierno Prim el 20 de agosto de 1870 , se votaria el candidato de los tres que tuviera más posibilidades de salir elegido.

35 DSC, 24 de abril de 1872, núm. 1, págs. 2 y 3.

36 Esto sirvió para que la discusión no derivara en una nueva crisis de Gobierno, dada la fortaleza de pruebas y los argumentos contra el fraude electoral que tenian preparados Castelar y Ruiz Zorrilla. DSC, 1 de mayo de 1872, ním. 8, págs. 68-88.

Hispania, LVII/3, núm. [97 (1997) 1107-1129 
El asunto de los 2 millones de reales sacados de la caja de Ultramar para pagar servicios del ministerio de Gobernación y fabricar una mayoría parlamentaria ${ }^{37}$, provocó, tras un agitado debate, la dimisión de Sagasta.

Si el apoyo de Cánovas a la opción conservadora de la Monarqufa amadeista se iba haciendo cada vez más manifiesta, se hizo aún mayor con el nuevo Gobierno Serrano, en el que introdujo a Luis Elduayen en el ministerio de Hacienda, y consiguí que Estrada fuera nombrado Presidente de la Comisión para la minoración del déficit del presupuesto. De esta manera, la mayoría gubernamental y los canovistas anularon las iniciativas de la oposición de republicanos y radicales, siempre unidos para derribar al Gobierno, como en el caso de la moción de censura de finales de mayo ${ }^{38}$.

La guerra contra los carlistas que se habían levantado en armas unos meses antes, aunque había finalizado formalmente con el tratado de Amorebieta, continuaba con algunas partidas de insurrectos. Serrano, Presidente del Gobierno, pidio entonces a Amadeo I la suspensión de las garantías constitucionales, a lo que el Rey se negó. Creyendo el duque de la Torre que esta negativa suponía haber perdido la confianza de Amadeo I, dimitió.

Cánovas pronunció, en los días que antecedieron a la prevista dimisión del Gobierno, su último discurso en las Cortes del Sexenio. Explicó toda su carrera política desde 1854. Declaró, como ya había hecho otras veces, su disposición inicial contraria al proyecto constitucional, pero su lealtad posterior a la legalidad vigente. La labor de todo hombre conservador de Gobierno, dijo, era respetar y hacer respetar la ley, evitar cualquier revolución, porque toda revolución, lejos de conseguir el orden, "no tiene otro fruto que la anarquía". Había sacrificado, continuó diciendo, todos sus principios políticos, por hacer prevalecer el orden y la libertad dentro de la Constitución de 1869. Había sido en las Constituyentes donde se formó espontáneamente el grupo liberal-conservador, por afinidad ideológica, con el único propósito de poner en común sus ideas en contra del proyecto constitucional, pero acordaron que, tras la aprobación del texto, se dejarían libertad para que cada uno emprendiera el camino político que deseara; $y$, aunque permanecieron juntos, nunca pretendieron formar un partido, sino, a lo más, un grupo parlamentario.

Ya en las Cortes del reinado de Amadeo, siguió contando Cánovas en su discurso, su único fin fue el de procurar que la política tomara un rumbo conservador. No creía que la combinación de fuerzas del Gobierno, un Ministerio de conciliación, pudiera por si sola asegurar el orden, sino que necesitaba el apoyo decidido de la Cámara. Esta razón le llevó a favorecer parlamentariamente la política de los gabinetes conservadores. Su alejamiento del poder, el no ocupar personalmente cargo alguno, fue voluntario, " $i \mathrm{O}$ es que no se

37 PI y Margall, ob. cil., pág. 76, afirma que cobran en el expediente comunicaciones de la policía secreta que lastiman la honra de los hombres más ilustres y alcanzan al mismo Amadeon, razón por ta cual, según el federal, Sagasta abandonó la presidencia.

${ }_{38}$ Fue una reprobación del Presidente del Congreso, Rios Rosas, presentada por el republicano Castelar y el radica! Romero Girón, y que fue desechada en votación nominal. En esta misma sesión Ruiz Zorrilla, renunció a su acta de diputado. DSC, 31 de mayo de 1872 , núm. 27 , págs. 526-536. 
puede apoyar a los Gobiernos, o es que no se pueden sostener las soluciones conservadoras, o cualesquiera otras soluciones políticas, sino con la mira de ocupar inmediatamente el poder?».

Explicó, finalmente, lo que entendía por conservador. Ser conservador era defender los interés de la propiedad en general y de las clases propietarias en particular, que son la base necesaria del orden social; defender, además, los intereses y las creencias religiosas, «que son otra base interior, pero más importante todavía, de ese mismo orden social». Y, por otro lado, ser conservador suponfa extender el influjo de tales principios para que la sociedad viviera sobre estas bases. En este sentido era en el que Cánovas reconocía a un Gobierno conservador, y por ésta razón «merece todo el apoyo de mi palabra, de mis sufragios y de mi conciencia». Acabó anunciando que el grupo liberal-conservador se disolvía para que sus miembros pudieran libremente seguir la conducta política que quisieran ${ }^{39}$.

Finalmente el Rey se vio obligado a llamar a Ruiz Zorrilla para formar Gobierno ${ }^{40}$. Las elecciones, celebradas del 24 al 27 de agosto, le depararon una mayoría más abultada aún que la fabricada por Sagasta -274 radicales, 77 republicanos federales, 14 constitucionales, 9 alfonsinos y 2 republicanos unitarios-, con lo que se aseguraba una Cámara complaciente con el ministerio. Topete y Serrano no se presentaron a las elecciones, Cánovas y Sagasta perdieron sus actas, y federales intransigentes -fracción del partido republicano-, parte de los alfonsinos y los moderados optaron por la abstención.

Fue en ese momento cuando la opción conservadora para la revolución de septiembre desapareció. Cánovas dio por fenecida la experiencia y se decidió abiertamente por la restauración del príncipe Alfonso y la construcción de una legalidad diferente. Escribió una carta de despedida a sus electores en la que afirmaba que no se realizaba el orden ni la libertad, y, que, "por inevitable consecuencia de ello, la cuestión dinástica está de nuevo planteada», y ya que la monarquía de Amadeo I era incapaz de ofrecer paz, «hoy más que nunca está la libertad de la patria en el restablecimiento de la monarquía hereditaria y legítima” ${ }^{41}$.

\section{CÁNOVAS EXTRAPARLAMENTARIO: ORGANIZACIÓN DEL ALFONSISMO}

\section{Contactos con los Borbones}

Con Isabel II en Francia desde la Revolución y el príncipe menor de edad, los trabajos políticos siguió llevándolos, al igual que antes de septiembre de

39 DSC, 11 de junio de 1872, núm. 36, págs. 877-881.

40 E] 13 de junio Topete anunció la dimisión del Gobierno Serrano, y Fernando Fernández de Córdova, Presidente Interino del Consejo de Ministros, suspendió las sesiones por esta legislatura. DSC, 13 y 14 de junio de 1872, núm. 37 y 38, págs. $905-909$ y 911-915, respectivamente.

41 Canovas del Castillo, A., Carta de despedida a los electores de los distritos de Cieza y Yecla, Madrid, Rivadeneyra, 1872. págs. 4-5 y 14-15."

Hispeniu. LVI/3, num. 197 (1997) 1107-1129 
1868 , la corte. La Reina destronada consultó varias veces antes de 1872 con Cánovas, además de con otros políticos unionistas, como Bermúdez de Castro, Calderón Collantes y Bertrán de Lis, sobre cuál debía ser su actuación, incluso pidió el golpe militar a Serrano, Prim, Caballero de Rodas y Espartero. Las respuestas de Cánovas fueron vagas y sin contenido político estratégico alguno.

Siguiendo el consejo de Marfori la Reina nombró al marqués de Novaliches único representante suyo en $1870^{42}$. A partir de entonces fue el marqués de Alcañices el que más trabajó para poner a Cánovas al frente del alfonsismo.

Al año de la consulta con todos aquellos que podían ayudar a los Borbones, Isabel II abdicó, el 25 de junio de 1870, en su hijo Alfonso. La restauración que deseaba la Reina difería en la forma y en el fondo con el plan canovista; Isabel II pretendía que fuera mediante un pronunciamiento como se produjese la vuelta al trono de España de los Borbones, y que fuera lo antes posible, sin esperar a que la causa alfonsina ganara terreno en la opinión pública. Sin embargo, debido al carácter cambiante de la Reina, abandonó esta opinión cuando el general Serrano, su mayor esperanza como abanderado de la restauración, se separó completamente de los alfonsinos en enero de 1873 . Igualmente, doña Isabel rechazaba todos y cada uno de los principios de la Constitución de 1869 , hecho que Cánovas no compartía, negándose incluso en un principio a que su hijo firmara un documento que contuviera el ideario de la restauración alfonsina y que, por ende, le comprometiera. Luego, tras hablar con Cánovas, aceptó la elaboración del manifiesto de Sandhurst, incorporando cambios y matizaciones.

\section{La jefatura del alfonsismo}

En septiembre de 1870 dejó Novaliches de representar al príncipe y se barajó la posibilidad de formar una junta compuesta por tres personas, aunque finalmente optaron por la jefatura única. La dirección del partido alfonsino pasó entonces por Pezuela, Lersundi, Calonge y Montpensier. Lersundi, que había sido capitán general de Cuba, era partidario de la restauración por obra de las armas ${ }^{43}$. Hasta 1873 hubo 5 planes para un pronunciamiento; el primero contó con una junta militar formada por Cheste, Gasset y Calonge e intentaron el concurso de Espartero, el cual se negó rotundamente; luego se sucedieron los planes de Lersundi, Reina, Caballero de Rodas y Calonge ${ }^{44}$.

42 FABlÉ, $o b$, cit., pág. 76

43 Fernández Almagro, Melchor, Cánovas, Su vida y su política, Madrid, Tebas, pág. 160

44 Espadas Burgos, Manuel, Alfonso XII y los orígenes de la Restauración, Madrid, CSIC, 1975, págs. 267-8. Los posteriores a enero de 1873 fueron protagonizados por el general Balmaseda y sus hombres, Martínez Campos, Gasset, Bassols, Marchesi e Iglesias - al que veremos, como general de la Guardia Civil encargada de la seguridad del Congreso de los Diputados, dar su aprobación personal a la entrada de las tropas de Pavia el 2 de enero de 1874-.

Hispania, LVIJ/3, nủm. 197 (1997) 1107-1129 
El 23 de septiembre de 1871 se llevó a cabo una reunión en el Palacio Basilewsky, en la que Isabel II se desprendió oficialmente de la jefatura de la familia real, entregándosela a su madre María Cristina. Cánovas del Castillo no fue a ese acto, como faltó también al de la abdicación, excusándose por carta ${ }^{45}$. Montpensier fue requerido por la Reina madre María Cristina para dirigir el partido alfonsino, y ser regente hasta la mayoría de edad de Alfonso, momento en que contraería matrimonio con la hija de Montpensier. El convenio de Cannes, que así se bautizó, fue negociado por Goicoerrotea y Pidal con el duque de Montpensier, y luego firmado por María Cristina el 15 de enero de 1872, e incluyó, aparte de lo ya apuntado, el acuerdo de no convocar Cortes Constituyentes ${ }^{46}$.

La desconfianza mutua entre Serrano, el único que podía en aquellos momentos conducir al Ejército por el camino restauracionista, y el jefe oficial del alfonsismo, el duque de Montpensier, provocó que no se entrevistaran directamente, y que éste último lo hiciera a través de representantes - Lersundi, Jacinto María Ruíz, e incluso Cánovas-. El acuerdo al que llegaron el general Serrano y Cánovas se ceñía a que éste último quedaría como único interlocutor entre el duque de la Torre y Montpensier; en convencer a la Reina de la necesidad de esperar el momento adecuado, y en el compromiso de que cada implicado en el proyecto alfonsino aportase cuantos medios económicos pudiera ${ }^{47}$.

El duque de Montpensier, no bien visto por el alfonsismo, devolvió los poderes a la Reina en enero de 1873, e Isabel II encargó a Jacinto María Ruíz negociaciones con Serrano, el cual no negó ni afirmó, que trabajaría por la Restauración ${ }^{48}$.

Cuando el 22 de agosto de 1873 recibió Cánovas la carta redactada por el marqués de Molins y firmada por la Reina Isabel y el príncipe Alfonso, en la que le otorgaron plenos poderes para hacer triunfar la Restauración ${ }^{49}$, la labor que había llevado para extender por toda España los ctrculos alfonsinos estaba culminando ${ }^{50}$.

45 FeRNÁNDEZ Almagro, ob. cit., pág. 193. Fabié dirá que no se le llamó, cosa que contradicen las cartas que aporta Fernández Almagro. FABlE, ob. cit., págs. 76-77

4h Espadas Burgos, ob, cil. pág. 181

47 El plan que propuso Serrano a Lersundi en diciembre de 1872 , era unir a todos los grupos políticos, salvo radicales y republicanos federales, bajo la bandera de Cuba Española, y una vez acabada la guerra proclamar al principe Alfonso. Este plan ilusionó a Isabel Il, sin embargo, el general Serrano to abandonó al mes siguiente. Villarrutia, Marqués de, El General Serrano, Madrid, Espasa Calpe, 1929, pág. 202. EsPaDAs, ob. cit., págs. 294-5.

48. LEMA, ob. cil., págs. $93-96$

49 FERNÁNDEZ AlmAGro, M., Historia politica de la España contemporánea, Madrid, Alianza Ed., 1972, 3.² ed., I, págs. 237-238.

so «Muerto Bermúdez de Castro, afíliado a la obra revolucionaria Posada Herrera, fallecido Bravo Murillo, convertido en el director del carlismo Nocedal, fracasada la confianza que se tenia puesta en Montpensier y Serrano, Cánovas polarizará más cada día en su torno las esperanzas de una restauración en el sentido pleno del término". DiEz DEL CORRAL, Luis, El liberalismo doctrinario, Madrid, 1973, pág. 594

Hixpania, LV15/3, núm. 197 (1997) 1107-1129 


\section{La construcción del partido liberal-conservador}

Mientras la corte de Isabel II continuaba con los juegos de poder, en Madrid, el 23 de marzo de 1872, el marqués de Alcañices reuní́ a unos cincuenta alfonsinos y postuló a Cánovas como jefe del partido. Una vez aceptado, Cánovas propuso la formación de una junta en la que estarían Luis Estrada, Francisco de Cárdenas, Saturnino Álvarez Bugallal, Manuel Quiroga Vázquez y Antonio Fabié. El comité se puso al habla con alfonsinos de otros lugares de la Península para extender, en círculos alfonsinos, la organización del partido ${ }^{51}$.

Cinco días después, el 28 de marzo, Ardanaz, fue encargado por Cánovas para entrevistarse con Bravo Murillo, el cual le dijo que la Restauración debía hacerse sin Ejército y tomando un carácter liberal, es decir, aceptando parte de los principios que informaban la Constitución de 1869.

La izquierdización del régimen septembrino fue evidente desde mediados de 1872. Los unionistas desesperaban de la marcha del Gobierno y del Parlamento, de manera que el general Rosell, en diciembre, pidió una entrevista a Cánovas, a la que éste no acudió, pero a la que mandó a Alvarez Bugallal, Quiroga y Fabié, y en la que se le propuso la dirección de la Unión Liberal. Cánovas se limitó a enviar una copia de la entrevista al marqués de Alcañices ${ }^{52}$.

La evidencia de la crisis política en enero de 1873 hizo de nuevo al Rey Amadeo considerar la necesidad de un Gobierno conservador. Pero con la ausencia de Serrano y Sagasta se decidió por Ríos Rosas, el cual aceptó, rodeándose de un grupo de posibles ministros unionistas. Manuel Silvela consultó con Antonio Fabié sobre la actitud de Cánovas del Castillo ante ese posible nuevo gobierno conservador ${ }^{53}$. Cánovas contestó que observaría la misma actitud colaboradora que la que tuvo con anteriores gobiernos de la coalición de septiembre.

Sin embargo, Amadeo present 6 su renuncia a la Corona el 8 de febrero ${ }^{54}$. Nada más proclamarse la República, los moderados, que habían combatido la

51 FABIÉ, ob. cit., pág. 78

52 Ibid., págs. 84-85

53 «Antes de decidir necesito saber cómo piensa Cánovas y conocer la actitud que tomaría frente al gobiemo de Unión liberal que se intenta constituir.(...) En resumen, sólo aceptaré ahora la cartera, si usted me da la seguridad de la benevolencia de Cánovas después de hablar con él.» Id., pág. 88

54 El Consejo de Ministros, tras la petición expresa al Rey de que esperara a que se resolviera la situación para hacerlo público, apuntaba varias soluciones. Montero Ríos, apoyado luego por Rivero, era partidario de una regencia trina formada por Espartero, el Presidente del Tribunal Supremo de Justicia y el almirante jefe de la armada _-Topete-, mientras las cámaras, en sesión conjunta, elegían nuevo rey. Martos se negó a aceptar una nueva solución monárquica y optó por la República. El 11 de febrero de 1873, reunidas las cámaras, en sesión conjunta, lo que era anticonstitucional, y sin la abdicación formal de Amadeo I, se proclamó la República por una proposición de Pi y Margall. Ibid., pág. 90.

Hispanid. LVII/3, núm. 197 (1997) 1107-1129 
actitud política de Cánovas en las Cortes del reinado que acababa de terminar, fueron a negociar su adhesión al proyecto canovista de Restauración. Se ensanchó el partido alfonsino, durante el período republicano, por la derecha, con elementos provenientes del moderantismo (como los casos entre otros de Orovio y Calderón Collantes) y, por la izquierda, con unionistas que habían participado en la Revolución de 1868 (como Romero Robledo, Ayala y Manuel Silvela). Los círculos alfonsinos, mientras tanto, se habian extendido por todo el país, logrando una influencia creciente en la opinión pública.

\section{Opinión publica, no militares}

Es corriente, definir a Cánovas como un constante conspirador que buscó el golpe militar para restituir a un Borbón en el trono de España, e incluso, calificar su proyecto de eúltima salida de la oligarquía española» ${ }^{55}$.

La democracia sólo era concebible para Cánovas - como para la mayor parte del pensamiento liberal--, sobre la base de una difusión generalizada de la propiedad, es decir, rechazaba la extensión de los derechos políticos a los no propietarios. Escindir aquellos de Ia propiedad desembocaba en la subversión del orden social y en el comunismo. A pesar de todo, Cánovas opinará que el sufragio universal será siempre una farsa, un engaño a las muchedum. bres, por el comunismo o la manipulación de las clases directoras ${ }^{56}$. Cánovas no era un demócrata, no creía en los derechos sin un Estado fuertemente represor, rechazaba el sufragio universal, dividía a la sociedad en minoría inteligente y muchedumbre ignorante, pero dos elementos le separan de los análisis al uso: la conquista de la opinión pública y el alejamiento de los militares como actores políticos determinantes.

En Bayona, en el verano de 1873, se reunieron algunos militares y políticos significados de la Revolución de Septiembre -entre los que destacaban Serrano y Martos-. Su objetivo era preparar un levantamiento que acabara con el federalismo, y gobernar con el nombre provisional de República hasta que se formaran unas Cortes constituyentes. Cánovas acudió a esta reunión y se opuso a todo: no aceptó el nombre de República y quiso que si no se restauraban los Borbones, hubiese un Gobierno provisional innominado, que preparase el retorno de estos últimos ${ }^{57}$.

El que estuviera en marzo de 1872 organizando el partido alfonsino no era incompatible ni con el apoyo a Gobiernos conservadores ni que aconsejara a sus amigos tomasen parte en ellos. Se trataba de llegar lentamente, por el

55 YLLÁN CALDERÓN, ob. cit., pág. 82

56 DSCC, 8 de abril de 1869, núm. 44, págs. 926-938; Discurso Il en el Ateneo, ob.cit, págs. 75, 79-80; Discurso IJI, «El problema religioso y sus relaciones con el político» (2 de noviembre de 1872), OO.CC., ob. cit. pág. 83 y 102; Discurso VII, «Soberania popular y democracia» (6 de noviembre de 1889), ibid., pág. 214; Discurso VIII, "La cuestión obrera y su nuevo carácter» (10 de noviembre de 1890 ), ibid., págs. 218-230.

57 Nido y Segalerva, ob. cit., págs. 390-391

Hispania, LVIL/3, aน́m. 197 (1997) 1[07.1129 
devenir espontáneo de los acontecimientos, a un régimen liberal-conservador que asegurara el orden. Para ello habia que ganarse la opinión, por lo que fomentó la prensa alfonsina. Cánovas se encargó de que los partidarios más pudientes aportaran dinero para esos periódicos.

Al tiempo, se extendió por todo el país una estructura provincial y local, a fin de que, si se producía una contienda electoral la opinión alfonsina se movilizara ${ }^{58}$. El sistema seguido por aquella propaganda era la confluencia de la prensa alfonsina con la fundación en capitales de provincias y en todas las ciudades importantes de círculos alfonsinos. Cánovas alentaba a la formación de dos tipos de centros - según una carta de éste a Torres-Cabrera jefe del alfonsismo cordobés-, uno, más conservador en el que tuvieran cabida «hasta los que la impaciencia ha hecho carlistas» ${ }^{59}$, y otro más liberal, en el que puedan acogerse los «desengañados de la revolución" "0; Cánovas participó en el círculo liberal alfonsino de Madrid.

Los centros alfonsinos estaban formados por las clases burguesas, aunque se había intentado también crear otros de extracción más popular. Los círculos, según cuenta Benoist ${ }^{61}$, eran «independientes de las juntas formadas por los jefes del partido para dirigir la propaganda y para sostener relaciones con el Comité central de Madrid, por una parte, y con las cercanías [sic.] de la familia real desterrada, por otra.» Fue el ex-unionista Romero Robledo el encargado en Madrid de dotar al partido de los cuadros cualificados suficientes para hacer la restauración; mientras que Cánovas dio el encargo al también exunionista Ayala para que, utilizando los Círculos hispano-ultramarinos que él había ayudado a formar, fundara una red política de opinión alfonsina ${ }^{62}$. Incluso se llegaron a formar escuadrones de voluntarios armados.

La situación política se había tornado más grave aún desde que los diputados seguidores de Pi y Margall y de Salmerón habían acordado separar a

54 Fernández Almagro, ob, cit., pág. 228

59 En noviembre de 1873 se publicaron los "Estatutos del Círculo Conservador alfonsino de Madridh, que en su art.64 indicaban que eran refundición de los estatutos y reglamento de 1870-. refiriéndose a un Círculo conservador que se fundó en Madrid en aquel año, y cuyos principios y reglas de organización eran exactamente las mismas que las que luego tendría el alfonsino; «Estatutos del Círculo conservador de Madrids, Tip.T.Fortanet, 1870- En su art.1 definia al círculo alfonsino como asociación política, literaria y de recreo; y en su art.2 establecia que, como asociación política, tenía por objeto propagar y defender, por los medios legales, los principios fundamentales de la sociedad -en el de 1870 «principios conservadores»-, «agrupando y armonizando los elementos que los constituyen bajo la bandera de la Monarquía Constitucional»s.

to Pirala, A., Historia Contemporánea. Anales desde 1843 hasta la conclusión de la iltima guerra civil, Madrid, Manuel Tello, 1875-77, t.lIl, pág. 309.

61 Benorst, Charles: Cánovas del Castillo, Ed.Literarias, Madrid, 1931, pág. I 80

62 Nido y Segalerva, ob. cit, pág. 398. Tanto Espadas Burgos como Piqueras Arenas, J. A., [La revolución democrática (1868-1874). Cuestión social, colonialismo y grupos de presión, Ed.de la Revista de Trabajo, Madrid, 1992], aunque con diferente alcance, hacen especial hincapié en la determinación que sobre la política canovista realizaron los intereses representados en estos círculos hispano-ultramatinos, si bien los planteamientos políticos y doctrinales de Cánovas se sostenián por si mismos. 
Castelar del Gobierno republicano, y los intransigentes estaban en disposición de acceder legalmente al poder con un Ministerio que relanzara la política federal. Tal estado de cosas, prevista desde octubre de 1873, incitó a los radicales y a los constitucionales de Sagasta y Serrano a unir esfuerzos y concebir planes que impidieran el rebrote del cantonalismo. En estas circunstancias, cuando Castelar perdió, finalmente, el voto de confianza en la madrugada del 3 de enero de 1874, hizo que Pavía, el cual anteriormente había tenido una conferencia con jefes de los partidos de la Coalición de septiembre -cuyas personalidades se desconocen-, disolviera la Asamblea. Pavía convocó a generales y civiles para formar un gobierno de conciliación que continuara con la República unitaria y tuviera como jefe absoluto por tiempo indefinido a Serrano ${ }^{63}$. Cánovas discrepó, y propuso la formación de un gobierno neutral y provisional, que preparase el advenimiento del príncipe Alfonso ${ }^{64}$. La República unitaria de Serrano se impuso como solución y Cánovas rechazó los ofrecimientos para formar parte del Gobierno. Este gesto fue entendido por algunos alfonsinos, especialmente militares, como una oportunidad perdida para traer la Restauración ${ }^{65}$, lo cual les llevó a creer en la solución de fuerza como la única posible ya.

Pero el rechazo de Cánovas del Castillo a un golpe militar databa de los albores de la Revolución del 68, y se manifestó claramente en sus discursos parlamentarios. El Ejército debía ser excluido de la escena política, no se debía buscar nuevamente en «las cuadras de los regimientos» el origen del poder público ${ }^{66}$. Para Cánovas todo régimen que se fundara por las armas, por esas mismas armas caería, tal y como la experiencia del siglo xIX español demostraba. Por esa razón se opuso a las intentonas durante 1874 del general Martínez Campos.

El general Balmaseda, hombre en la sombra que dirigió gran parte de las intentonas militares, envió al capitán de artillería Federico Sánchez Bedoya a entrevistarse con Cánovas, el cual lo rechazó durante veinte días, consiguiendo al final, el 28 de agosto de 1874, hablar con Romero Robledo y Fabié en el madrileño paseo de la Castellana. Tras una agitada discusión, el capitán afirmó que los generales harían Rey de España al príncipe Alfonso antes de tres meses ${ }^{67}$.

Belmonte, hombre de Cánovas, y el general Cheste, propiciaron una reunión a finales de noviembre de 1874 , a la que asistieron el propio Cánovas y Romero Robledo. Recapitularon sobre las fuerzas militares con las que podían contar, llegando a la conclusión de que sólo disponían de dos briga-

63 Los asistentes fueron los hermanos De la Concha (el marqués del Duero y el de la Habana), Martos, Rivero, Sagasta, Becerra, Elduayen, Cánovas, Topete, el general Beranger y Eugenio Montero Ríos. ESPADAS BURGOS, ob. cil., pág. 387

*4 LEMA, ob. cit., págs. 106-107. BENOIST, ob. cit., pág. 162

ns Esta ocasión "perdida» no fue sólo percibida así por algunos alfonsinos, Nicolás Estévanez, ministro de la Guerra en el Gobierno de Pi, también era de la misma opinión, cuando afirmaba que los alfonsinos podían haberse hechos dueños de la situación el 3 de enero si no se hubiera opuesto el general Pavía. EstévaneZ, N., Mis memorias, Madrid, Tebas, 1975, pág. 273.

t6 DSCC, 6 de junio de 1870 , núm. 299, págs. 8621-41; DSC, 11 de junio de 1872, núm. 36 , págs. 877-881.

67 FABIE, ob. cit., pág. 100

Hispania. LVII/3, núm. 197 (1997) 1107-1129 
das. Nada se resolvio, según dice Cheste en sus papeles ${ }^{68}$. Tampoco Martínez Campos, que se encontraba presente, explicó su plan, porque lo más probable era que ni aún lo hubiera concebido. El general Balmaseda, disgustado por la dimensión liberal del manifiesto de Sandhurst, al igual que otros militares, aceleró el pronunciamiento, y el 26 de diciembre envió al marqués de Alcañices a presentar el plan a Cánovas, el cual lo desaprobó completamente.

El plan militar de Cánovas se limitaba a un pacto con el general De la Concha ${ }^{69}$, consistente en que tras la prevista victoria sobre los carlistas en Estella, éste enviaría a dos oficiales a Madrid a que pidieran al Gobierno de Serrano y Sagasta que proclamara al príncipe Alfonso rey de España. Pero De la Concha murió en el asedio de Estella y el plan militar de Cánovas fracasó ${ }^{70}$.

Durante todo el período previo a la Restauración Cánovas se hizo con el favor de los generales más significados, con el ánimo de controlarlos y convencerlos de que esperaran a la multiplicación de la opinión alfonsina. Se trataba de evitar la iniciativa del Ejército, sin dejar de contar con su apoyo en el momento decisivo ${ }^{71}$.

Este desconfianza hacia la opción militar también venía fomentada por los planes del general Serrano para salir de la interinidad política que encabezaba a raíz del golpe de Pavía. El duque de la Torre encargó a Andrés Borrego la negociación con los alfonsinos, sobre la base de reconocer la provisionalidad de la Jefatura del Estado de Serrano, dada la situación de desorden público, a cambio de la convocatoria de unas Cortes generales y extraordinarias. Según este plan, una vez derrotados los carlistas, el general Serrano depondría ante las Cortes que habian de ser elegidas la autoridad que ostentaba. A la reunión en Madrid, durante la cual Borrego explicó esta propuesta, acudieron los dirigentes locales del alfonsismo, y no Cánovas, que al parecer se hallaba fuera de la capital ${ }^{72}$. Los alfonsinos madrileños, tras unos días, en los que con toda seguridad se consultó a Cánovas, contestaron que sólo era posible tal acuerdo una vez que Serrano ganara la campaña de Bilbao contra los carlistas. Una circular de Sagasta, Presidente del Gobierno, a finales de año, vino a abreviar plazos, ya que manifestaba el deseo de poner fin a la interinidad de Serrano y convocar Cortes sin esperar al fin de la guerra ${ }^{73}$.

68 Rozalejo, Marqués de, Cheste o todo un siglo, Espasa Calpe, Madrid, 1935, pág. 257.

69 El encargado de negocios francés recogía en un despacho del 9 de junio de 1873 unas palabras del general $\mathrm{De}$ la Concha, marqués del Duero, en las que se definía como alfonsino, pero afirmando que en el caso de que se proclamara rey de España en aquellos momentos al príncipe Federico Carlos Hohenzollern —con el advenimiento de la República, la cuestión dinástica se abrió de nuevo-, él pondría su espada a su servicio. EsPadas BuRgos, ob. cit., pág. 35

70 VARela ORTEGa, José, Los amigos políticos. Partidos, elecciones y caciquismo en la Res. tauración (I875-1900), Alianza, Madrid, 1977, págs. 37-38.

7 FERNANDEZ AlMAGRo, ob. cit., págs. 235-236

72 CAstro, Concepción de, Romanticismo, periodismo y política. Andrés Borrego, Tecnos, Madrid, 1975, págs. 334-335.

73 Ibid., pág. 337. CASTRO, Concepción de, «Entre la Revolución y la Restauración: el régimen provisional de 1874», 1973 [artículo escrito para el número proyectado por la revista «lberia» en el centenario de la Primera República, que fínalmente no fue editadọ; cortesía de la autora]. 
La posibilidad que el plan de Borrego y la circular de Sagasta abrían para conseguir una Restauración parlamentaria, gracias a los escaños que el Gobierno «concediera» a los partidarios de Cánovas, más los que éste ganara merced a los círculos alfonsinos, se enfrentaba en el ánimo del político conservador a la profunda desconfianza que sentía por Serrano -el «Mac Mahon español»—. Además, el deseo de Cánovas, tal y como él venía expresando desde finales de 1872, era el éxito de una Restauración civil, conseguida mediante la presión de la opinión pública, y el reconocimiento del príncipe Alfonso como heredero legítimo de la Corona de España; y no a través de la elección en Cortes como pretendían Serrano y Sagasta, ni con un pronunciamiento como deseaban Balmaseda y Martínez Campos, que, al igual que le ocurrió a don Amadeo, hubieran hecho depender la Monarquía, en el futuro, de una Constitución y unos políticos, términos estos que doctrinalmente Cánovas no aceptaba.

De esta manera, la noche del 29 de diciembre, cuando Cánovas del Castillo fue informado del pronunciamiento de Martínez Campos, escribio, desde la celda del Gobierno civil en la que le había metido el capitán general de Madrid, Primo de Rivera, un texto en el que rechazaba el pronunciamiento y afirmaba que el alfonsismo nada tenía que ver con ello. El documento iba a ser publicado en La Época, pero José Ignacio Escobar, su director, hizo que se perdiera en el camino a la redacción del periódico ${ }^{74}$.

\section{CONCLUSIóN}

El examen de la trayectoria de Cánovas durante el Sexenio revolucionario demuestra que no fue un conspirador, y que colaboró con la fracción de la Coalición de septiembre más decidida a consolidar las instituciones de la Constitución de 1869. En primer lugar, apoyó el mantenimiento de la conciliación entre las diferentes tendencias revolucionarias porque creía, al igual que Serrano y Sagasta, que éste era el mejor medio para dar estabilidad al nuevo régimen; $\mathrm{y}$, en segundo lugar, cuando progresistas de Ruiz Zorrilla y demócratas de Rivero y Martos se decidieron por la ruptura de la Coalición, Cánovas alentó a la formación de la opción conservadora como mecanismo imprescindible de toda Monarquía constitucional, pensamiento que era compartido por el propio Amadeo de Saboya.

Tampoco conspiró cuando el régimen se decantó por la izquierda revolucionaria, ya a finales de 1872, y ni siquiera cuando con la Primera República el desorden y el desprestigio institucional eran enormes. Cánovas planeó y desarrolló un proyecto civil moderno, no intentado aún en la España de la

74 Marfil, Mariano, Los silencios políticos de Cánovas, conferencia pronunciada en el Ateneo el 8 de marzo de 1928, centenario del nacimiento de Cánovas, en CÁnovas del Castillo, Obras Completas, t.I, Fundación Cánovas del Castillo, Madrid, 1981. Marfil afirma que esta acción de Escobar sirvió para que la Restauración siguiera adelante.

Hispania, LVIJ/3, núm. 197 (1997) \107-1129 
época, de extensión y organización de la opinión favorable a una Restauración liberal en el príncipe Alfonso de Borbón. Es más, relegó a los militares en su proyecto, se negó a cualquier golpe de fuerza, y buscó eliminar para siempre el pronunciamiento como instrumento de cambio político. Para Cánovas, el príncipe Alfonso no debía ser Rey por elección parlamentaria, como don Amadeo de Saboya, ni por un pronunciamiento, como deseaba e hizo Martínez Campos, sino que los partidos, la opinión pública, el Ejército y las Cortes reconocieran y proclamaran a don Alfonso de Borbón heredero legítimo de la dinastía histórica a la Corona de España. 